\title{
Mitigating financial fragility with Continuous Workout Mortgages ${ }^{\sqrt{3}}$
}

\author{
Robert J. Shiller ${ }^{\mathrm{a}}$, Rafał M. Wojakowski ${ }^{\mathrm{b}, *}$, M. Shahid Ebrahim ${ }^{\mathrm{c}}$, Mark B. Shackleton ${ }^{\mathrm{b}}$ \\ ${ }^{a}$ Cowles Foundation for Research in Economics, International Center for Finance, Yale University, New Haven \\ CT 06520-8281, USA \\ ${ }^{b}$ Lancaster University Management School, Department of Accounting and Finance, Lancaster LA1 4YX, UK \\ ${ }^{c}$ Bangor Business School, Bangor University, Hen Goleg, College Road, Bangor, LL57 2DG North Wales, UK
}

\begin{abstract}
This paper models Continuous Workout Mortgages (CWMs) in an economic environment with refinancings and prepayments. CWMs are home loans whose balance and payments are indexed using a market-observable house price index of the pertaining locality. Our main results include: (a) explicit modelling of repayment and interest-only CWMs; (b) closed form formulæ for mortgage payment and mortgage balance of a repayment CWM; (c) a closed form formula for the actuarially fair mortgage rate of an interest-only CWM. For repayment CWMs we extend our analysis to include two negotiable parameters: adjustable "workout proportion" and adjustable "workout threshold." These results are of importance as they not only help in the understanding of the mechanics of CWMs and estimating key contract parameters, but they also provide insight on how to enhance the resilience of the financial architecture and mitigate systemic risk.
\end{abstract}

JEL classification: C63; D11; D14; D92; G13; G21; R31

Keywords:

Continuous Workout Mortgage (CWM), Repayment, House price index, Prepayment intensity, Cap and floor on continuous flow.

\footnotetext{
${ }^{\star}$ Special thanks are owed to Amy Crews Cutts, Douglas A. McManus and Dogan Tirtiroglu. We are grateful to Brent Ambrose, Kevin Atteson, Richard Buttimer, Peter Carr, Jing (Maggie) Chen, Paul Doukhan, Bernard Dumas, Piet Eichholtz, Borys Grochulski, Joseph Langsam, Jean-Luc Prigent, John Wilson, seminar participants at Cergy, Edinburgh, Glasgow, Maastricht, ICMA Reading, Morgan Stanley NYC and conference participants at AREUEA mid-year 'policy meeting' Washington DC, Bachelier Congress Toronto, Financial Sector Performance $\&$ Risk (Post-Crisis) Bangor and ASSA Denver for helpful suggestions.

${ }^{*}$ Corresponding author. Tel.: +44(1524)593630; fax: +44(1524)847321.

Email addresses: robert.shiller@yale.edu (Robert J. Shiller), r.wojakowski@lancaster .ac.uk (Rafał M. Wojakowski), m.s.ebrahim@bangor.ac.uk (M. Shahid Ebrahim), m.shackleton@lancaster.ac.uk (Mark B. Shackleton)

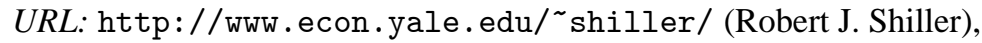
http://www.lancaster.ac.uk/staff/wojakows/ (Rafał M. Wojakowski)
} 
The U.S. financial system is in tatters. It is time to build from scratch.

Dennis K. Berman (2008, p. 19)

The ongoing financial crisis has exposed the vulnerability of the most sophisticated financial structures to systemic risk. This crisis-emanating from mortgages to borrowers with high credit risk-has devastated the capital base of financial intermediaries on both sides of the Atlantic. Its impact on the real sector of the economy has given rise to fear and uncertainty not seen since the Great Depression of the 1930s (see Reinhart and Rogoff, (2008); and Diamond and Rajan, (2008)).

The fragility of the financial intermediaries stems from the rigidity of the traditional mortgage contracts such as the Fixed Rate Mortgages (FRMs), Adjustable Rate Mortgages (ARMs) and their hybrids (see Stiglitz (1988); Campbell and Cocco (2003); Green and Wachter (2005); and Reinhart and Rogoff (2008)). Modigliani (1974, p. 1) reiterates this quite strongly when he states that: "As long as loan contracts are expressed in conventional nominal terms, a high and variable rate of inflation - or more precisely a significant degree of uncertainty about the future of the price level - can play havoc with financial markets and interfere seriously with the efficient allocation of the flow of saving and the stock of capital." In order to make it more resilient and mitigate systemic risk, this necessitates reforming the financial architecture to include facilities that can better absorb shocks in the financial system

One such solution studied in this paper is that of Continuous Workout Mortgages (CWMs) as expounded in Shiller (2008a), (2009b), (2008b) and Feldstein (2009). This facility eliminates the expensive workout of a defaulting rigid plain vanilla mortgage contract. This subsequently reduces the risk exposure of financial institutions and thus the government to their bailouts. CWMs share the price risk of a home with the lender and thus provide automatic adjustments for changes in home prices or incomes. Mortgage balances are thus adjusted and monthly payments are varied automatically with changing home prices. This feature eliminates the rational incentive to exercise the costly option to default which is embedded in the loan contract. Despite sharing the underlying risk, the lender continues to receive an uninterrupted stream of monthly payments. Moreover, this can occur without multiple and costly negotiations. 
Unfortunately, prior to the current crisis CWMs have rarely been considered. The academic literature, with the exception of Ambrose and Buttimer (2012), has not discussed its mechanics and especially its design. Shiller is the first researcher, who forcefully articulates the exigency of its employment. CWMs were conceived in his (2008b) and (2009b) studies $1{ }^{1}$ as an extension of the well-known Price-Level Adjusted Mortgages (PLAMs), where the mortgage contract adjusts to a narrow index of local home prices instead of a broad index of consumer prices. In their recent study, Ambrose and Buttimer (2012) numerically investigate properties of Adjustable Balance Mortgages which bear many similarities to CWMs. Alternatively, Duarte and McManus (2011) stipulate creation of derivative instruments written on credit losses of a reference mortgage pool. Our simple and fully analytic model complements the more intricate one of Ambrose and Buttimer (2012). We rely on a methodology which allows valuation of optional continuous flows (see e.g. Carr, Lipton and Madan (2000) and Shackleton \& Wojakowski (2007)).

For lenders to hedge risks, continuous workout mortgages need indicators and markets for home prices and incomes. These markets and instruments already exist:2 For example, the Chicago Mercantile Exchange (CME) offers options and futures on single-family home prices. An example of this are the Real Estate MacroShares launched on NYSE in May 2009. Furthermore, reduction of moral hazard incentives requires inclusion of the home-price index of the neighborhood into monthly payment formula. This is to prevent moral hazard stemming from an individual failing to maintain or, worse, damaging the property just to reduce mortgage payments. Likewise, occupational income indicators matter along with the borrower's actual income. This is again to prevent moral hazard stemming from an individual deliberately losing a job just to reduce mortgage payments.

We feel that CWMs retain the positive attribute of PLAMs in reducing purchasing power risk (see Leeds (1993)). They, however, improve upon PLAMs by reducing prepayment, default and interest rate risks, since the borrower shares in the risk of the housing market. This implies

\footnotetext{
${ }^{1}$ See Shiller (2003) for home equity insurance.

${ }^{2}$ Creation of new markets for large macroeconomic risks is discussed in Shiller (1993). For derivatives markets for home prices see Shiller (2009a).
} 
that borrowers participate in the appreciation of the property during any positive economic event such as an interest rate decrease, which compensates prepayment risk. Nonetheless, borrowers participate in the depreciation of the property during any negative economic event, thereby reducing default risk. This is because a CWM aims to prevent the mortgage balance exceeding the value of the property, thus keeping the embedded default option (at or) out of the money at all times. Therefore, during the tenure of a mortgage which is comprised of periods of varying economic cycles (including changing interest rates) CWMs are anticipated to defray associated risks. The only risk which CWMs (like PLAMs) currently cannot cure is liquidity risk. This, however, can be expected to reduce over time by their securitization and eventual deployment (in sufficient volume).

We implicitly assume the existence of an information infrastructure, where property rights, foreclosure procedures (needed for real estate to serve as collateral) and accurate methods of valuing property are well established (see Levine, Loayza and Beck (2000)). This assumption facilitates the underwriting of mortgages in a complete market setting, where contracts spanning each state of the economy are clearly and unambiguously written. This presumes that information costs are not very acute in real estate finance for the following reason. Real estate lenders (the principals in a debt contract) can costlessly decipher any proprietary (ex-ante) information held by borrowers (the agents in a debt contract) by trading financial claims over a multi-period horizon. This is deduced from the literature on multi-period insurance contracting (see Hosios and Peters (1989)). In the "real world," lenders also have access to information on ex-post risk and return on various classes of properties to help them underwrite their facilities appropriately. ${ }^{3}$

We also draw parallels between CWMs and Shared Income Mortgages (SIMs) discussed

\footnotetext{
${ }^{3}$ The above assumption does not imply that the financial intermediaries are unaware of dangers posed by the twin issues stemming from information asymmetry (i.e., adverse selection and moral hazard). These intermediaries have to be extra vigilant in case of CWMs as they share in the risk of the underlying collateral (i.e., the home). This necessitates the careful structuring of the mortgages to mitigate both issues as follows: (1) Adverse Selection is alleviated by releasing funds in the escrow process when the title of the specific property being purchased is exchanged for cash; (2) Moral Hazard is dissipated dynamically as advocated in Pagès (2009). This is conducted by continuously monitoring the borrower (and the underlying collateral) in conjunction with mandating the following in the mortgage covenant: (i) minimum maintenance on the property; (ii) payment of taxes; and (iii) adequate insurance coverage. See Smith and Warner (1979) for more information on debt contracting using covenants.
} 
in Ebrahim, Shackleton and Wojakowski (2011). This helps us derive closed form solutions to price variants of CWMs based on observable inputs of local home prices. Finally, we provide examples, where exogenous variables governing CWMs imputed from real world observations involving individual home prices, house price indices, individual incomes, occupational income indicators, etc.

This paper is structured as follows. Section 1 initiates the pricing of CWM with a simple model involving an interest only contract. This is extended to the amortizing CWM in Section 2 and to CWMs with a protective threshold included in Section 3. Finally, we provide concluding comments in Section 6 ,

\section{Interest-only Continuous Workout Mortgage}

To begin, we provide a simple example of a CWM, whose payment is continuously readjusted based on the current house price index of a location. To simplify our setup we focus on interest only mortgages with repayment maturity $T$. A property is acquired at time $t=0$ for initial cost $H_{0}$. Subsequent values of the house are not observable until the time of its sale. In lieu of this information a house price index of the area $\bar{H}_{t}$ is observed for all times $t \geq 0$. To make things even simpler we assume that: (i) the loan to value ratio is $100 \%$; (ii) the constant, risk free market interest rate is $r$; and (iii) $i$ is the mortgage rate. If the mortgage were an "ordinary" interest only mortgage, the borrower would pay the continuous interest flow $i H_{0} d t$ plus a lump sum principal repayment $H_{0}$ at maturity. The risk free discounted present value of such payments equals

$$
V=\int_{0}^{T} e^{-r t} i H_{0} d t+e^{-r T} H_{0}=i \frac{H_{0}}{r}\left(1-e^{-r T}\right)+e^{-r T} H_{0}
$$

For an actuarially fair loan this present value should be equal to the initially borrowed amount, i.e. $V=H_{0}$, which gives $i=r$.

Now consider the home value weighted by the local home price index $\bar{H}_{t}$ and its initial value $\bar{H}_{0}$

$$
h_{t}=H_{0} \frac{\bar{H}_{t}}{\bar{H}_{0}}, \quad \text { so that } h_{0}=H_{0} .
$$


A continuous workout mortgage can be designed to protect the homeowner against falls in the home value and the consequence of potential default. For the entire interval $0<t \leq T$ i.e. including maturity $T$, the intermediate balance of the loan on which interest payments are based can be adjusted to

$$
\min \left\{h_{0}, h_{t}\right\}=h_{0}-\max \left\{0, h_{0}-h_{t}\right\}=h_{0}-\left(h_{0}-h_{t}\right)^{+},
$$

in lieu of $H_{0}$. That is, the initial balance plus a short position in a put option on a house price index with a strike price of $h_{0}=H_{0}$. Substituting the above relationship the formula giving the expected present value of the loan becomes

$$
\bar{V}=V-\frac{i}{r} \int_{0}^{T} E\left[e^{-r t}\left(r h_{0}-r h_{t}\right)^{+}\right] d t-E\left[e^{-r T}\left(h_{0}-h_{T}\right)^{+}\right] .
$$

The value $\bar{V}$ is an expected present value as $h_{t}$ and $h_{T}$ are random variables contingent on a house price index. Expectations $(E)$ are computed under a risk-neutral measure consistent with discounting at the riskless rate. Risk neutral valuation is employed because the house price index $\bar{H}_{t}$ is traded and can be hedged.

Note that $\bar{V}$ is less than $V$ as the consumer obtains protection against price falls. The last term is in fact a protective put issued at the money. The intermediate term is equal to the ratio of interest rates $i / r$ times an integral of put options written on a continuum of maturities from $t=0$ to $t=T$. This integral is in fact a floor on flow $r h_{t}$ issued at the money. Under appropriate assumptions (i.e. geometric Brownian motion governing the dynamics of the house price index $\left.\bar{H}_{t}\right)$ the value of this floor, $P\left(r h_{0}, r h_{0}, T, r, \delta, \sigma\right)$, can be computed analytically employing the closed form expressions developed in Shackleton and Wojakowski (2007) (see Appendix Appendix A). Likewise, the value of the last term in (4), $p\left(h_{0}, h_{0}, T, r, \delta, \sigma\right)$, can be expressed using the Black-Scholes (1973) formula. Parameters $\delta, \sigma$ are, respectively, the service flow and volatility of the house price index (see Appendix Appendix A).

The goal is now to establish the actuarially fair mortgage rate $i$ for this CWM. This calculation is of utmost importance for prospective originators of continuous workouts. While the mortgage balance adjusts systematically and automatically, the mortgage rate $i$ should be 
established only once as a part of the contract, remaining constant until maturity. Using $V$ from (1) and setting $\bar{V}=H_{0}$ and $h_{0}=H_{0}$ yields

$$
H_{0}=i \frac{H_{0}}{r}\left(1-e^{-r T}\right)+e^{-r T} H_{0}-\frac{i}{r} P\left(r H_{0}, r H_{0}, T, r, \delta, \sigma\right)-p\left(H_{0}, H_{0}, T, r, \delta, \sigma\right),
$$

where the floor $P$ is an integral of Black-Scholes puts $p$

$$
P\left(r \bar{H}_{0}, r \bar{H}_{0}, T, r, \delta, \sigma\right)=r \int_{0}^{T} p\left(\bar{H}_{0}, \bar{H}_{0}, t, r, \delta, \sigma\right) d t
$$

Solving (5) for $i$ gives the mortgage interest rate.

Proposition 1. An interest-only Continuous Workout Mortgage (CWM) with protective put and floor has the mortgage interest rate $i$ equal to

$$
i=r\left[\frac{H_{0}\left(1-e^{-r T}\right)+p\left(H_{0}, H_{0}, T, r, \delta, \sigma\right)}{H_{0}\left(1-e^{-r T}\right)-P\left(r H_{0}, r H_{0}, T, r, \delta, \sigma\right)}\right] .
$$

The above formula confirms our intuition on the constitution of a continuous workout mortgage. If both protective put $(p)$ and floor $(P)$ are deep out of the money (as can be the case when house prices are expected to strongly appreciate), then $p, P \rightarrow 0$ and $i \rightarrow r$. However, when this is not the case and the market anticipates a possibility of a price fall (as can be the case following a bubble), both put and floor are in the money and $i>r$ on new deals. This implies that the market prices the insurance offered by the continuous workout as an ex ante increase of the mortgage rate $i$.

\section{Put Figure C.1 And Table B.1 about here}

Furthermore, the required interest $i$ increases with risk $\sigma$ consistent with option pricing theory. Interestingly, increasing risk even to $\sigma=30 \%$ does not have a great impact on $i$, as illustrated in Figure C.1 and Table B.1. For a typical loan with $T=30$ years to maturity, riskless rate $r=5 \%$ and a service flow $\delta=1 \%$ the impact amounts to only an increase of $0.37 \%$ above 5\%. Surprisingly, insuring the house price level is less costly as interest rates become higher. However, such guarantees are more expensive when time to maturity is short and when the service flow is higher. The maturity effect is due to all options (i.e. the put and the floor) in this example being issued at-the-money, thereby insuring price levels of the property at the 
time of issuance. More time to maturity implies that the house has more chance to appreciate and the guarantee to depreciate. Likewise, the service flow effect is due to intensive property use and lower maintenance, which decreases its value making the guarantee more expensive. The $\delta$ represents a service flow to the occupier that erodes capital gains in the home value $H$ and therefore cannot be shared with the lender. The higher the interest, the lower the impact of service flow and thus the lower the vulnerability to moral hazard.

Table B.1 gives numerical values of annual payments when the risk free interest rate is $r=$ $5 \%$. Interest-only continuous workouts are compared to the corresponding fixed-rate mortgages for different values of service flow, $\delta=1 \%$ and $\delta=4 \%$. Note that fixed rate $(r=5 \%)$ mortgage payments do not depend on the service flow.

From an analytical perspective, equation (7) is equivalent to the riskless rate $r$ times a fraction. To facilitate this interpretation, we re-write it as

$$
i=r\left[\frac{H_{0} e^{-r T}-H_{0}-p\left(H_{0}, H_{0}, T, r, \delta, \sigma\right)}{P\left(r H_{0}, r H_{0}, T, r, \delta, \sigma\right)-\frac{r H_{0}}{r}\left(1-e^{-r T}\right)}\right] .
$$

The numerator of the fraction represents the present value $H_{0} e^{-r T}$ of the forward sale of the house at price $H_{0}$, minus the initial value of the house $H_{0}$, minus the cost of the put protection $p\left(H_{0}, H_{0}, T, r, \delta, \sigma\right)$ to be paid through an increased mortgage interest rate $i$. The denominator, meanwhile, represents the intermediate period cash flows where interest payments accommodate the cost of insurance. It is equal to the value of the floor $P\left(r H_{0}, r H_{0}, T, r, \delta, \sigma\right)$ written on continuous flow $r H_{0}$ minus the value of annuity $\frac{r H_{0}}{r}\left(1-e^{-r T}\right)$, based again on the same continuous flow $r H_{0}$. Intuitively, this annuity is still paid at rate $r$ with the interest on difference $r\left(H_{0}-H_{t}\right)$ added back to $P\left(r H_{0}, r H_{0}, T, r, \delta, \sigma\right)$ when $H_{t}<H_{0}$.

From an economic perspective the above fraction is a ratio of two values, each corresponding to a set of transactions. The first set of transactions-collected in the numerator of $(8)$ occur at the beginning and at the end of the interval $[0, T]$. The appropriate marginal discount rate for this protected forward sale is $r$. By contrast, transactions within the interval $(0, T)-$ collected in the denominator of (8) - must earn the marginal rate $i>r$ to offset the added 
insurance ${ }^{4}$ In equilibrium, both marginal costs must be equal yielding $i$.

Proposition 2. An interest-only Continuous Workout Mortgage (CWM) has mortgage interest $i$ and mortgage interest spread $\frac{i-r}{r}$ independent of initial property value $H_{0}$ equal to

$$
i=r\left[\frac{1-e^{-r T}+p(1,1, T, r, \delta, \sigma)}{1-e^{-r T}-P(r, r, T, r, \delta, \sigma)}\right]
$$

and

$$
\frac{i-r}{r}=\frac{p(1,1, T, r, \delta, \sigma)+P(r, r, T, r, \delta, \sigma)}{1-e^{-r T}-P(r, r, T, r, \delta, \sigma)}
$$

Proof. Use (7) and the homogeneity properties for put and floor

$$
p(\alpha S, \alpha K, T, r, \delta, \sigma)=\alpha p(S, K, T, r, \delta, \sigma), \quad P(\alpha s, \alpha k, T, r, \delta, \sigma)=\alpha P(s, k, T, r, \delta, \sigma)
$$

where $\alpha$ is a constant, $S, K$ are values [\$] and $s, k$ are flows [\$/yr.]. For $\alpha=H_{0}$ the initial property value, $H_{0}$, cancels out from the numerator and denominator of (7).

Property (9) is very useful as it allows quoting mortgage interest rate $i$ to a (potential) borrower without knowing the value of the house to be purchased. This estimation is based on the maturity of the loan, several market parameters and only needs the information that the house value is determined at arms length. With the exception of the riskless interest rate $r$, the parameters-such as the (average) service flow $(\delta)$ and the house price volatility $(\sigma)$ of the locality-relate to the dynamics of the house price index and can be estimated from data. Likewise, the second property (10) provides a useful estimation of the mortgage spread.

\section{Repayment Continuous Workout Mortgage}

A major innovation during the years of Great Depression was fully amortizing mortgages (see Green and Wachter (2005)). They represent the most popular type of residential mortgages in the US and are known as Fixed Rate Mortgages (FRM). In this section we extend the concept of full amortization to introduce Repayment CWMs (RCWMs).

\footnotetext{
${ }^{4}$ In the current CWM insurance is added against random decline of terminal property value $H_{T}$ as well as against intermediate falls in property value $H_{t}, t<T$, that negatively impact on the value of interest payments before maturity.
} 
In a FRM the repayment flow rate $(R)$ is fixed in time and the balance $Q_{t}$ fully amortizes to zero at maturity (that is, $Q_{T}=0$ ). The amount owed to the lender at time $t$

$$
Q_{t}=\int_{t}^{T} R e^{-r(s-t)} d s=\frac{R}{r}\left(1-e^{-r(T-t)}\right)
$$

is equal to the present value of remaining payments and is essentially an amortization identity. Differentiating (12) with respect to time $t$ we can check that the dynamics of $Q_{t}$ is fully deterministic indeed and described by the ordinary differential equation

$$
\frac{d Q_{t}}{d t}=r Q_{t}-R
$$

(with terminal condition $Q_{T}=0$ ). It implies a growth in the balance $Q_{t}$ at rate $r$ offset by progressive constant mortgage payment flow $R$. The mortgage can be fully repaid when the interest flow on principal $r Q_{t}$ is lower than the coupon flow $R$, in which case the repayment $R$ is a well-known function of the interest rate $r$, the initial balance $Q_{0}$ and the maturity $T$

$$
R=\frac{r Q_{0}}{1-e^{-r T}}
$$

We argue that a Repayment Continuous Workout Mortgage (RCWM) should scale down the repayment flow $R$ when the house price index of the location decreases. To indicate that the repayment flow of a RCWM changes with time as a function of the initial home value weighted by the local house price index let's introduce notation $R\left(h_{t}\right)$. Furthermore, we assume that the mortgage payment flow is linearly scaled down to

$$
R\left(h_{t}\right)=\min \left\{\rho, \rho \frac{\bar{H}_{t}}{\bar{H}_{0}}\right\}=\rho \min \left\{1, \frac{h_{t}}{h_{0}}\right\},
$$

so that $R\left(h_{t}\right) \rightarrow 0$ automatically produces a full workout when prices drop $h_{t} \rightarrow 0$. Parameter $\rho$ provides the cap on repayment flow under RCWM. Clearly, if the mortgage is fairly priced, parameter $\rho$ must be greater than $R$. We can think of the difference $\rho-R>0$ as equal to the price of the insurance to be paid in good states of nature for the continuous workout automatically provided in bad states of nature.

This setup fully protects the homeowner against a decline in the value of property because 
the repayment flow $R\left(h_{t}\right)$ decreases whenever the house price index is below its initial value. The repayment flow attains its maximal value and becomes constant (equal to $\rho$, where $\rho$ is a constant to be determined) whenever the house price index is above its initial value. In this case repayments of a RCWM behave in the same way as repayments of a standard fully amortizing mortgage. However, the maximal repayment flow of a RCWM $(\rho)$ must be set at a level higher than the repayment flow of a corresponding standard fully amortizing mortgage. That is, $\rho>R$ (see Proposition 4).

A partial workout will provide partial protection with the mortgage payment only partly scaled down to

$$
R_{\alpha}\left(h_{t}\right)=\rho \min \left\{1,1-\alpha\left(1-\frac{h_{t}}{h_{0}}\right)\right\}=\rho\left[1-\alpha\left(1-\frac{h_{t}}{h_{0}}\right)^{+}\right],
$$

where $0 \leq \alpha \leq 1$. Depending on the value of $\alpha$, the repayment flow can be adjusted continuously between full protection $(\alpha=1)$ and none at all $(\alpha=0)$. For $\alpha=0$ the repayment flow becomes constant equal to $\rho$. In this particular case the RCWM reduces to the well-known, classic case of fully amortizing repayment mortgage. The reduction of mortgage payment $R_{\alpha}\left(h_{t}\right)$ as a function of current adjusted house price level $h_{t}$ and for different "workout proportions" $(\alpha)$ is illustrated in Figure C.2.

\section{Put Figure C.2 ABout Here}

Note that due to the stochastic nature of the repayment flow there is (in general) no guarantee that the mortgage will be repaid in full. This is the case when the maturity of the loan is kept fixed and the values of $\alpha$ are strictly greater than zero. Indeed, in the worst case scenario of $h_{t}$ suddenly dropping to zero repayments of a full workout $(\alpha=1)$ also drop to zero. Mortgage repayments (16) are random, contingent on future values of the house price index. Fortunately, it is possible to accurately price this random stream of cash flows as follows.

The expected present value under the risk-neutral measure gives the mortgage balance

$$
Q_{t}=E_{t}\left[\int_{t}^{T} R_{\alpha}\left(h_{s}\right) e^{-r(s-t)} d s\right]=E_{t}\left[\int_{t}^{T} \rho\left(1-\alpha\left(1-\frac{h_{s}}{h_{0}}\right)^{+}\right) e^{-r(s-t)} d s\right] .
$$


Since

$$
\frac{h_{s}}{h_{0}}=\frac{\bar{H}_{s}}{\bar{H}_{0}}
$$

we derive

$$
Q_{t}=\int_{t}^{T} \rho e^{-r(s-t)} d s-\frac{\rho \alpha}{r \bar{H}_{0}} E_{t}\left[\int_{t}^{T}\left(r \bar{H}_{0}-r \bar{H}_{s}\right)^{+} e^{-r(s-t)} d s\right] .
$$

Clearly, the first integral is given by (12) while the expectation in the second integral is computed in closed form from to the floor formula on flow $\left\{r \bar{H}_{s}\right\}_{s=t}^{T}$ with strike level $r \bar{H}_{0}$ for all $t$ (see Shackleton and Wojakowski (2007))

$$
\begin{aligned}
E_{t}\left[\int_{t}^{T}\left(r \bar{H}_{0}-r \bar{H}_{s}\right)^{+} e^{-r(s-t)} d s\right] & =r \int_{t}^{T} p\left(\bar{H}_{t}, \bar{H}_{0}, s-t, r, \delta, \sigma\right) d s \\
& =P\left(r \bar{H}_{t}, r \bar{H}_{0}, T-t, r, \delta, \sigma\right)
\end{aligned}
$$

where $p$ and $P$ are the corresponding put and floor (see Appendix Appendix A). Combining the above formulas we get the following Proposition.

Proposition 3. The mortgage balance of a Repayment Continuous Workout Mortgage (RCWM) at time $t \in[0, T]$ is equal to

$$
Q_{t}=\frac{\rho}{r}\left[1-e^{-r(T-t)}-\frac{\alpha}{\bar{H}_{0}} P\left(r \bar{H}_{t}, r \bar{H}_{0}, T-t, r, \delta, \sigma\right)\right],
$$

where $\bar{H}_{0}$ and $\bar{H}_{t}$ are values of the house price index at times of origination $(t=0)$ and the semi-closed interval $t \in(0, T]$.

Clearly, for $\alpha=0$ we recover the full repayment case (12). Furthermore, with $\alpha>0$ and for the same $\rho$, the mortgage balance of a RCWM is lower. That does not mean, however, that a full repayment mortgage and a RCWM both originating at the same time $t=0$ will have the same $\rho$. On the contrary, a RCWM has a higher mortgage payment flow $\rho$. The intuition is that for a given "workout proportion" $\alpha \in[0,1]$, the mortgage payment flow $\rho$ must be computed at origination to compensate for the guarantee against house price decline provided by a RCWM.

Proposition 4. For a given "workout proportion" $\alpha \in[0,1]$, the mortgage payment flow parameter is given by

$$
\rho=\frac{r Q_{0}}{1-e^{-r T}-\frac{\alpha}{H_{0}} P\left(r H_{0}, r H_{0}, T, r, \delta, \sigma\right)},
$$

where $Q_{0}$ is the initial value of the loan. 
Remark 5. The mortgage payment flow $\rho$ is a constant parameter which is computed at origination $(t=0)$ for the duration of the contract. It should not be confused with mortgage payment $R_{\alpha}\left(h_{t}\right)$ given by equation (16) which is a function of randomly changing adjusted house price level $h_{t}$. Mortgage payments $R_{\alpha}\left(h_{t}\right)$ decrease when home prices decline.

Remark 6. For $\alpha=0$ the mortgage becomes a standard repayment type. Equation (23) yields $\rho=R$ in accordance with equation (14).

Equation (23) is critical for potential originators of continuous workouts with repayment features. This pricing condition helps us evaluate the maximal annual payment for this mortgage. A broker can instantly compute this quantity on a computer screen and make an offer to a customer. More importantly, different levels of protection can be offered to different borrowers.

In fact all brokers in the world use a special version of this formula already. This is because for $\alpha=0$ equation $(23)$ yields the value of mortgage payment for the unprotected, standard repayment mortgage, defined by equation (14). Since $P>0$ it is clear that the protection commands a higher payment, as $\alpha>0$ implies $\rho>R$.

\section{Put Table B.2 about here}

For a 30-year repayment mortgage the continuous workout premium is not very large making RCWMs very attractive. As summarized in Table B.2, in a typical situation when interests are $5 \%$ and volatility is $15 \%$, the mortgage payment increases from $\$ 6.44$ thousand a year for a standard fixed rate repayment mortgage, to $\$ 6.82$ thousand a year for a corresponding full continuous workout. This is for an initial loan of $\$ 100$ thousand and when the service flow rate is $1 \%$. Therefore, the full protection costs only $\$ 383.41$ a year, i.e., it only adds about $\$ 31.95$ to a monthly repayment of about $\$ 536.34$.

\section{Put Figure C.3 ABout here}

From Figure C.3 we also observe that the service flow rate $\delta$ does not influence the standard repayment level (no workout, $\alpha=0$, flat dotted line). However, adding a continuous workouts (full $\alpha=1$ or partial $\alpha=\frac{1}{2}$ ) to a property with higher service flow (e.g. $\delta=1 \%$ or $\delta=4 \%$ ) increases the monthly insurance premium only slightly. Lines for partial protection $\left(\alpha=\frac{1}{2}\right)$ lie only minimally below half-way between lines for $\alpha=1$ and $\alpha=0$. For $\delta=4 \%$ and $\sigma=30 \%$, 
for example, the endpoint of the line for partial protection is located at 11.46, only slightly below the midpoint 11.55. For lower volatilities the partial protection premium converges exactly to the midpoint, unless the service flow parameter $\delta$ is larger than the riskless rate, in which case (not reported on Figure C.3) this line is lower than the midpoint, even for low volatilities.

\section{Put Figure C.4 ABout here}

Finally, it is interesting to note that the cost of protection-in terms of basis points that are added to standard repayment by full protection-is higher at lower interest rates. See Figure C.4. This spread essentially mimics the behaviour of an at the money put option as a function of the interest rate $r$.

Similarly, the evaluation of mortgage balances can be done using (22). This is a very important information when the customer sells the house and prepays the mortgage. This expression is also of practical importance for computation of annual mortgage statements which are typically sent to customers at each year end.

\section{Repayment CWM with Protective Threshold}

A significant increase in home prices leads to a considerable increase in mortgage payments. If such an increase is faster than the growth in household income, it leads to a drain on discretionary income (see Wilcox (2009)). This section therefore studies RCWMs with a protective threshold.

Wilcox (2009) —in a comment on Shiller's (2009b) paper—is of the view that households would still be willing to accept this risk as they would be able to extract equity from their appreciating homes as discretionary income. He, however, fails to observe that this risk would already be priced ex ante by the calculation of an appropriate mortgage rate. The higher the risk assumed by the household, the lower the mortgage rate would be.

There are, in fact, several ways to fine-tune a CWM to make it less or more expensive. One such tuning parameter is $\alpha$ for repayment CWM which specifies the proportion of response of 
mortgage balance. If the workout proportion $\alpha$ is set higher than 0 and closer to 1 , the household benefits from a lower mortgage balance in poor states of the economy but must assume a higher mortgage repayment flow $\rho$ parameter on a daily basis. 5 Conversely, if the household sets $\alpha$ closer to 0 (corresponding to the case of fixed rate standard repayment mortgages) it sets a lower repayment flow. This, however, leads to a higher mortgage balance in poor states of the economy. Thus, by setting lower repayments, the household bears a higher risk of negative equity during times of house price downturns.

A second way is to set a different protection threshold, higher or lower than the initial house price index level $\bar{H}_{0}$. If, for example, we set a lower threshold $\bar{K}<\bar{H}_{0}$, the protection kicks-in only after house values fall below $\bar{K}$. For such a CWM the household then repays

$$
R_{\alpha}\left(h_{t}, k\right)=\rho \min \left\{1,1-\alpha\left(1-\frac{h_{t}}{k}\right)\right\}=\rho\left[1-\alpha\left(1-\frac{h_{t}}{k}\right)^{+}\right]
$$

where

$$
k=\frac{H_{0}}{\bar{H}_{0}} \bar{K}<H_{0} .
$$

Note that in the special case when the strike price $\bar{K}$ equals $\bar{H}_{0}$ (or, equivalently, $k=h_{0}$ ), the repayment rate (24) reverts back to (16). A selectable protection threshold thus effectively defines a new family of CW mortgages which we term as Threshold Repayment Continuous Workout Mortgages. To use Figure C.2 to illustrate (24) i.e. how the threshold protection works, assume e.g. $h_{0}=120$ and $k=100$. Automatic workout will start when $h_{t}$ falls below the threshold $k=100$.

Proposition 7. The mortgage balance of a Threshold Repayment Continuous Workout Mortgage (TRCWM) at time $t \in[0, T]$ is equal to

$$
Q_{t}=\frac{\rho}{r}\left[1-e^{-r(T-t)}-\frac{\alpha}{\bar{K}} P\left(r \bar{H}_{t}, r \bar{K}, T-t, r, \delta, \sigma\right)\right],
$$

where $\bar{H}_{t}$ is the value of the house price index at time $t \geq 0$ and $\bar{K}$ is the "protection threshold."

Proof. We have

$$
Q_{t}=E_{t}\left[\int_{t}^{T} \rho\left[1-\alpha\left(1-\frac{h_{s}}{k}\right)^{+}\right] e^{-r(s-t)} d s\right]
$$

\footnotetext{
${ }^{5}$ Recall that $\rho$ defines the maximal annual repayment for a CWM i.e. the payment in good states of the economy, when housing values appreciate.
} 
Using $\frac{h_{s}}{k}=\frac{\bar{H}_{s}}{\bar{K}}$ we get

$$
Q_{t}=\int_{t}^{T} \rho e^{-r(s-t)} d s-\frac{\rho \alpha}{r \bar{K}} \int_{t}^{T} E_{t}\left[\left(r \bar{K}-r \bar{H}_{s}\right)^{+} e^{-r(s-t)}\right] d s .
$$

The first integral is given by

$$
\int_{t}^{T} \rho e^{-r(s-t)} d s=\frac{\rho}{r}\left(1-e^{-r(T-t)}\right)
$$

while the expectation in the second integral is computed in closed form from to the floor formula on flow $\left\{r \bar{H}_{s}\right\}_{s=t}^{T}$ with strike $r \bar{K}$ evaluated at time $t$ (see Shackleton and Wojakowski $(2007))$

$$
\begin{aligned}
\int_{t}^{T} E_{t}\left[\left(r \bar{K}-r \bar{H}_{s}\right)^{+} e^{-r(s-t)}\right] d s & =r \int_{t}^{T} p\left(\bar{H}_{t}, \bar{K}, s-t, r, \delta, \sigma\right) d s \\
& =P\left(r \bar{H}_{t}, r \bar{K}, T-t, r, \delta, \sigma\right)
\end{aligned}
$$

where $p$ and $P$ are the corresponding put and floor (see Appendix Appendix A). Substituting (31) and (29) into 28) we derive 26).

Similarly, setting $t=0$ and solving for $\rho$ in $(26)$ we derive the mortgage payment parameter of a TRCWM.

Proposition 8. For a given "workout proportion" $\alpha \in[0,1]$, the mortgage payment flow of a Threshold Repayment Continuous Workout Mortgage (TRCWM) is given by

$$
\rho=\frac{r H_{0}}{1-e^{-r T}-\frac{\alpha}{\bar{K}} P\left(r \bar{H}_{0}, r \bar{K}, T, r, \delta, \sigma\right)},
$$

where $H_{0}$ is the initial value of the loan, $\bar{H}_{0}$ is the initial value of the house price index and $\bar{K}$ is the "protection threshold."

Proof. For $t=0$ equation $(26)$ becomes

$$
Q_{t}=\frac{\rho}{r}\left(1-e^{-r T}-\frac{\alpha}{\bar{K}} P\left(r \bar{H}_{0}, r \bar{K}, T, r, \delta, \sigma\right)\right)
$$

Substituting $Q_{0}=H_{0}$ and solving for $\rho$ gives (32).

\section{Put Figure C.5 about here}

Figure C.5 illustrates how a high threshold $\bar{K}$ commands a higher maximal repayment $\rho$ for the household to benefit from higher reduction of mortgage balance $Q_{t}$ (scaled for given $\rho$ and 
$r$ ). The higher the threshold $\bar{K}$, the earlier the workout kicks in, providing a greater reduction of the mortgage balance in poor states of the economy. In the particular case of no protection $(\bar{K} \rightarrow 0)$, a CWM reverts back to the standard repayment mortgage. The mortgage payment $\rho$ converges to a constant value equal to $R$ given by (14).

\section{Refinancing and Prepayment of CWMs}

Refinancing constitutes a major risk faced by financial institutions as it leads to termination of profitable businesses at inopportune moments. Lenders also face prepayment risk because they don't know for how long a loan will be outstanding. This section therefore addresses this crucial issue.

Financial institutions can mitigate the refinancing risk by imposing a penalty to deter potentially mobile borrowers or those who flip properties frequently. The penalty in this section is designed so as to mimic those found in alternative mortgages like subprime (see Chomsisengphet and Pennington-Cross (2006)) and is in the spirit of Stanton and Wallace (1998). It can be evaluated using the methodology described below.

Empirical evidence confirms that borrowers do not prepay optimally, i.e. they do not maximize the loss to the lender. Reasons for prepaying typically include a sale of the property due to: a) change of employment and relocations; b) change in family composition (e.g. births, children leaving for university); c) a natural disaster, accident or non-strategic default of the borrower followed by insurance indemnity payment. These factors are relatively constant in time and are often modelled in the mortgage industry using the constant Conditional Prepayment Rate (CPR) convention or the Public Securities Association (PSA) benchmark (see e.g. Fabozzi (2005)). These professional conventions do not explicitly model prepayments due to refinancings which typically occur at an increased rate during periods of decreasing interest rates.

Prepayments can be modelled using a hazard rate (prepayment intensity) approach. The random prepayment time $\tau_{p}$ is modelled as a Poisson process with intensity $\lambda$ and is independent of state variables governing the processes for house prices. Formally, information in the model is described by an enlarged filtration $\mathscr{G}$, generated by the Brownian motion $Z_{t}$ 
and the prepayment indicator process $\mathbf{1}_{\left\{t \leq \tau_{p}\right\}}$ (see equation 34 below and e.g. Bielecki and Rutkowski (2002)).

Financial institutions typically impose a dollar prepayment penalty $\Pi_{\tau_{p}}$ at refinancing time $\tau_{p}$. It is often a fixed fraction $\alpha$ of the principal outstanding $Q_{\tau_{p}}$ and is imposed if refinancing occurs before some lock-in date $T^{*}$

$$
\Pi_{\tau_{p}}=\alpha Q_{\tau_{p}} \mathbf{1}_{\tau_{p}<T^{*}}=\left\{\begin{array}{cl}
\alpha Q_{\tau_{p}} & \text { if } \tau_{p}<T^{*} \\
0 & \text { otherwise }
\end{array}\right.
$$

The prepayment penalty is attractive only to long term investors who like to match the cost of financing with the income and the growth in the value of the asset instead of their alternative mortgage permanent income (see Hurst and Stafford (2004); Doms and Krainer (2007)).

In practice, the contract is negotiated so that no prepayment occurs within the short term. For interest-only Continuous Workout Mortgages (see Section 1) the value of the mortgage at origination is equal to the expected value of outstanding cash flows

$$
M_{0}=E[\underbrace{\int_{0}^{T} \mathbf{1}_{t<\tau_{p}} e^{-r t} c_{t} d t}_{\text {payments }}+\underbrace{\mathbf{1}_{0<\tau_{p} \leq T} e^{-r \tau} S_{\tau_{p}}}_{\text {prepayment }}+\underbrace{\mathbf{1}_{T<\tau_{p}} e^{-r T} S_{T}}_{\text {repayment }}]
$$

Working out expectations with respect to random prepayment time $\tau_{p}$ gives

$$
M_{0}=E\left[\int_{0}^{T} F(t) e^{-r t} c_{t} d t+\int_{0}^{T} g(t) e^{-r t} S_{t} d t+F(T) e^{-r T} S_{T}\right]
$$

where the expectation remains to be taken along the house price risk dimension. In the first integral and in the last term above

$$
F(t)=\operatorname{Pr}\left(t<\tau_{p}\right)=e^{-\lambda t}
$$

is the cumulative probability of the loan surviving beyond time $t$ and, in the middle term, $g(t)$ is the probability density of the loan being prepaid within time interval $(t, t+d t]$ i.e.

$$
g(t)=\frac{d}{d t}(1-F(t))=\lambda e^{-\lambda t}
$$


Defining the adjusted principal of a CWM outstanding at time $t \in[0, T]$ as

$$
Q_{t}=\min \left\{h_{0}, h_{t}\right\}=h_{0}-\left(h_{0}-h_{t}\right)^{+},
$$

we can also express the remaining components of 36 :

- $c_{t}$ is the value of continuous payments received until prepayment date or maturity, whichever comes first

$$
c_{t}=i Q_{t}
$$

- $S_{t}$ is the lump sum payment received if prepayment occurs before maturity, and is equal to principal outstanding $Q_{t}$ plus applicable prepayment penalty $\Pi_{t}$ (if any);

$$
S_{t}=Q_{t}+\Pi_{t}
$$

- $S_{T}$ is the lump sum payable at the tenure of the CWM if prepayment did not occur, i.e. any capital outstanding

$$
S_{T}=Q_{T}
$$

Note that (42) implies that if prepayment did not occur before maturity, the principal must be repaid in full. The other important assumption is that the house price index of the locality is used to estimate the automatic workout if prices depreciate. Alternatively, if a prepayment occurs, the property can be re-appraised or a sale will reveal its value $H_{\tau_{p}}$ (or $H_{T}$ at maturity).

As long as prepayment does not occur early $\left(t<\tau_{p}\right)$ the lender receives $c_{t}$ i.e., the contractual interest flow which automatically incorporates the continuous workout. Furthermore, if prepayment does not occur before maturity $\left(T<\tau_{p}\right)$, the lender receives the principal as a lump sum on maturity. Otherwise, if prepayment occurs at time $\tau_{p} \in(0, T)$, the interest flow ceases immediately and the lender receives a lump sum corresponding to the workout-adjusted principal payback and prepayment penalty (if any).

Using (37) and (38) in (36) the value of the mortgage at origination can be shown to be equal to

$$
M_{0}=E\left[\int_{0}^{T} e^{-(r+\lambda) t}\left(c_{t}+\lambda S_{t}\right) d t+e^{-(r+\lambda) T} S_{T}\right]
$$


Proposition 9 (CWM valuation equation). In an economic environment with prepayments, the relationship linking contractual parameters (contract rate $i$ and early prepayment penalty $\alpha$ ) of a Continuous Workout Mortgage to other exogenous parameters is given by

$$
\begin{aligned}
M_{0} & =H_{0}+H_{0}(i-r) \frac{1-e^{-(r+\lambda) T}}{r+\lambda}+\lambda \alpha H_{0} \frac{1-e^{-(r+\lambda) T^{*}}}{r+\lambda} \\
& -P\left((i+\lambda) H_{0},(i+\lambda) H_{0}, T, r+\lambda, \delta+\lambda, \sigma\right) \\
& -P\left(\lambda \alpha H_{0}, \lambda \alpha H_{0}, T^{*}, r+\lambda, \delta+\lambda, \sigma\right) \\
& -p\left(H_{0}, H_{0}, T, r+\lambda, \delta+\lambda, \sigma\right)
\end{aligned}
$$

where $T^{*}$ is the last date the penalty (34) is chargeable, while $P$ and $p$ are closed-form expressions for floor and at-the-money put given in Appendix Appendix A.

Remark 10. The value of the put in (44) can be expressed as the probability of the mortgage loan surviving until maturity time $T$ (the higher the intensity of prepayment, $\lambda$, the lower this probability) multiplied by an otherwise identical at-the-money European put option on the property

$$
p\left(H_{0}, H_{0}, r+\lambda, \delta+\lambda, \sigma, T\right)=e^{-\lambda T} p\left(H_{0}, H_{0}, r, \delta, \sigma, T\right) .
$$

Proof. Substituting (40), (41) and (42) into (43) we get

$$
M_{0}=E\left[\int_{0}^{T} e^{-(r+\lambda) t}\left[i Q_{t}+\lambda\left(Q_{t}+\Pi_{t}\right)\right] d t+e^{-(r+\lambda) T} Q_{T}\right] .
$$

Grouping terms and introducing the penalty (34) gives

$$
M_{0}=E\left[\int_{0}^{T} e^{-(r+\lambda) t}\left[(i+\lambda) Q_{t}+\lambda \alpha Q_{t} \mathbf{1}_{t<T^{*}}\right] d t+e^{-(r+\lambda) T} Q_{T}\right]
$$

Distributing the expectation operator over the plus sign yields

$$
M_{0}=E\left[\int_{0}^{T} e^{-(r+\lambda) t}(i+\lambda) Q_{t} d t\right]+E\left[\int_{0}^{T^{*}} e^{-(r+\lambda) t} \lambda \alpha Q_{t} d t\right]+E\left[e^{-(r+\lambda) T} Q_{T}\right] .
$$

Using expression (39) for the current balance, the first expectation can be computed as

$$
\begin{aligned}
E\left[\int_{0}^{T} e^{-(r+\lambda) t}(i+\lambda) Q_{t} d t\right] & =(i+\lambda) H_{0} \int_{0}^{T} e^{-(r+\lambda) t} d t \\
& -(i+\lambda) E\left[\int_{0}^{T} e^{-(r+\lambda) t}\left(h_{0}-h_{t}\right)^{+} d t\right] \\
& =(i+\lambda) H_{0} \frac{1-e^{-(r+\lambda) T}}{r+\lambda} \\
& -P\left((i+\lambda) H_{0},(i+\lambda) H_{0}, T, r+\lambda, \delta+\lambda, \sigma\right),
\end{aligned}
$$

where $P$ is given by the floor formula (see Appendix Appendix A). Similarly, the second ex- 
pectation in 48 is equal to

$$
\begin{aligned}
E\left[\int_{0}^{T^{*}} e^{-(r+\lambda) t} \lambda \alpha Q_{t} d t\right] & =\lambda \alpha H_{0} \frac{1-e^{-(r+\lambda) T^{*}}}{r+\lambda} \\
& -P\left(\lambda \alpha H_{0}, \lambda \alpha H_{0}, T^{*}, r+\lambda, \delta+\lambda, \sigma\right) .
\end{aligned}
$$

The third expectation in (48) can be expressed using the Black-Scholes at the money put formula (see Appendix Appendix A)

$$
E\left[e^{-(r+\lambda) T} Q_{T}\right]=H_{0} e^{-(r+\lambda) T}-p\left(H_{0}, H_{0}, T, r+\lambda, \delta+\lambda, \sigma\right)
$$

Replacing expectations (49), (50) and (51) in (48) and after some algebra then gives (44).

The main difficulty in (44) is computing expressions giving the floor value

$$
P\left(X_{0}, k, \rho, \phi, \sigma, T\right)=\int_{0}^{T} E\left[e^{-\rho t}\left(k-X_{t}\right)^{+}\right] d t=\int_{0}^{T} e^{-\lambda t} E\left[e^{-r t}\left(k-X_{t}\right)^{+}\right] d t
$$

where $\rho=r+\lambda$ and $\phi=\delta+\lambda$ i.e. sums of floorlets on $X$ struck at $k$ over a continuum of maturities $t \in[0, T]$. In the last integral in 52 ) each floorlet is weighted by the probability $e^{-\lambda t}$ that the loan will "survive" beyond $t$. This is because each $\left(k-X_{t}\right)^{+}$will be due only if the loan was not prepaid before $t$. These sums can be interpreted as weighted floors on flow $X_{t}$. In our setup flows $X_{t}$ are generated by prepaid "fractions" of the property value $\lambda H_{t}$ and $\lambda \alpha H_{t}$ (see Remark that follows). Weighted floors can be computed following the closed-form solution developed in Shackleton and Wojakowski (2007) (see Appendix Appendix A).

Remark 11. Flows in both expressions for finite floors $P$ appearing in (44) are written on flows $i H_{t}+\lambda H_{t}$ and $\lambda \alpha H_{t}$. Flow $i H_{t}$ results from regular interest payment, while $\lambda H_{t}$ and $\lambda \alpha H_{t}$ can be interpreted as effective flows resulting from prepayments statistically occurring at rate $\lambda$. Initial values of these flows enter the two floor functions $P$ appearing in (44). A bank securitizing CWMs after bundling them into portfolios will effectively be exposed to both flows $\lambda H_{t}$ and $\lambda \alpha H_{t}$. The former flow results from earlier principal repayments due to prepayments at rate $\lambda$ throughout the lifetime $[0, T]$ of the product. The latter flow represents the supplementary principal fraction $\alpha$ accruing at rate $\lambda$ during period $\left[0, T^{*}\right]$ when early prepayment penalty is charged.

In order to eliminate arbitrage the value of the mortgage at origination, $M_{0}$, must be equal to the value of the loan outstanding, $H_{0}$

$$
M_{0}=H_{0} \quad \text { (no arbitrage condition) }
$$


Furthermore, in expression (44) the first two arguments of the floor function $P$ have been presented so as to visualize their "flow" character: $(i+\lambda) H_{0}$ is an amount of money per annum. However, because the floor function inherits the homogeneity property from puts (i.e. from floorlets, of which it is a sum), expression (44) can be simplified further. After factorization and elimination of $H_{0}$, we obtain the following identity, which links a weighted sum of two annuities (left hand side) with a weighted sum of two floors and one put (right hand side)

$$
\begin{aligned}
(i-r) \times A(1, r+\lambda, T) & \\
+\lambda \alpha \times A\left(1, r+\lambda, T^{*}\right) & =(i+\lambda) \times P(1,1, T, r+\lambda, \delta+\lambda, \sigma) \\
& +\lambda \alpha \times P\left(1,1, T^{*}, r+\lambda, \delta+\lambda, \sigma\right) \\
& +p(1,1, T, r+\lambda, \delta+\lambda, \sigma),
\end{aligned}
$$

where we used the annuity function

$$
A(x, \rho, \tau)=\frac{x}{\rho}\left(1-e^{-\rho T}\right)
$$

The right hand side of (54) takes into account the benefits to the lender per unit value of housing. Similarly, the left hand side takes into account the costs. The benefits (costs) to the lender (homeowner) are:

1. The insurance premium paid by the homeowner;

2. The expected early prepayment penalty paid by the homeowner.

The costs (benefits) to the lender (homeowner) are:

1. The expected continuous workout paid to the homeowner;

2. The expected decrease of prepayment penalty when there is workout early:

3. The expected terminal workout paid to the homeowner.

Not surprisingly, identity (54) does not depend on the level of housing $H_{0}$. Moreover, it can be solved explicitly for the mortgage rate $i$ or for the early prepayment penalty parameter $\alpha$. It

\footnotetext{
${ }^{6}$ Early workout will lower the outstanding balance $Q_{t}$, to which the prepayment penalty is proportional here.
} 
is also possible to solve (44) for the contract rate $i$ explicitly and represent it as a function of market data and other inputs (such as the prepayment rate $\lambda$ ) and constraints. (See for example equation (57) below.)

Remark 12. When $M_{0}=H_{0}$ and in absence of prepayment penalties $(\alpha=0)$ the CWM valuation equation simplifies to

$$
\begin{aligned}
\underbrace{\frac{H_{0}(i-r)}{r+\lambda}\left(1-e^{-(r+\lambda) T}\right)}_{\text {Insurance premium (annuity) }} & =\underbrace{P\left((i+\lambda) H_{0},(i+\lambda) H_{0}, T, r+\lambda, \delta+\lambda, \sigma\right)}_{\text {Continuous Workout }} \\
& +\underbrace{p\left(H_{0}, H_{0}, T, r+\lambda, \delta+\lambda, \sigma\right)}_{\text {Terminal Workout }}
\end{aligned}
$$

i.e. in absence of arbitrage the extra income generated by charging the customer the premium $i-r>0$ must compensate for the cost of continuous workout insurance expressed by the floor $P$ (intermediate, continuous workouts) and the put $p$ (automatic workout at maturity). The total cost of insurance can be expressed as an annuity adjusted for prepayment and must be equal to the Continuous Workout component plus the Terminal Workout component.

\section{Numerical Illustration}

This section illustrates CWM valuation in a world with prepayment risk by focusing on the case of a CWM for which also $\alpha>0$ and $T^{*}>0$. This case is particularly important for residential mortgages where early prepayment penalties are invariably imposed in practice. Note that unlike the case without prepayment and in addition to terms expressing income from early prepayment penalty, valuation now depends on the sum of floorlets weighted by the probability of the mortgage "surviving" over the time period $[0, T)$. This quantity is analytically expressed by the floor function $P\left((i+\lambda) H_{0},(i+\lambda) H_{0}, T, r+\lambda, \delta+\lambda, \sigma\right)$.

Some key parameters can be expressed explicitly. For example, given parameters such as the prepayment rate $\lambda$, prepayment penalty fraction $\alpha$ and lock-in time $T^{*}$ we can explicitly compute the contract rate $i$ as follows

$$
i=r \times \frac{\frac{r}{r+\lambda} H_{0}\left(1-e^{-(r+\lambda) T}\right)-\frac{\lambda \alpha}{r+\lambda} H_{0}\left(1-e^{-(r+\lambda) T^{*}}\right)+P_{\lambda, T}+\alpha P_{\lambda, T^{*}}+p}{\frac{r}{r+\lambda} H_{0}\left(1-e^{-(r+\lambda) T}\right)-P_{r, T}}
$$

\footnotetext{
${ }^{7}$ This can be seen in the left hand side of 56 , where the discount rate of the annuity is $r+\lambda$ ( $\lambda$ is the prepayment intensity parameter) and the annual "coupon" of the annuity is $H_{0}(i-r)$.
} 
where

$$
P_{u, \tau}=P\left(u H_{0}, u H_{0}, \tau, r+\lambda, \delta+\lambda, \sigma\right): u=\lambda, r ; \quad \tau=T, T^{*}
$$

and

$$
p=p\left(r H_{0}, r H_{0}, T, r+\lambda, \delta+\lambda, \sigma\right) .
$$

When $\lambda=0$ (no prepayment) and $T^{*}=0$ or $\alpha=0$ (no early prepayment penalty) we recover the expression (7). Here too, it is readily seen that in fact $H_{0}$ can be eliminated from (57) to obtain expressions similar to (8) and (9). This means that there is no size effect, i.e. the contract rate $i$ is an intensive parameter, insensitive to the size of the loan and thus to the size of the property.

Equation (57) implies that the contract rate $i$ can be decreased by higher prepayment penalties $\alpha$. A further reduction in the contract rate $i$ is achieved by extending the lock-in period $T^{*}$ towards maturity $T$. This is, however, not immediate to be seen from (57). Therefore, to illustrate the sensitivity of the contract rate $i$ to various inputs we present a numerical example assuming the following case:

\begin{tabular}{|l|r|rl|}
\hline market interest rate & $r$ & $10 \%$ & p.a. \\
\hline service flow rate & $\delta$ & $7.5 \%$ & p.a. \\
\hline house price volatility & $\sigma$ & $1 \%, 5 \% \& 10 \%$ & p.a. \\
\hline term & $T$ & 30 & years \\
\hline lock-in period & $T^{*}$ & 5 & years \\
\hline prepayment penalty & $\alpha$ & none \& 5\% & of outstanding balance \\
\hline
\end{tabular}

We further assume that an individual, initially paying $i=10 \%$ per annum on a standard mortgage loan without prepayment penalties (base case) is offered to refinance his mortgage. A zero-profit bank offers a set of alternative mortgages, with and without prepayment penalties. Figure C.6 summarizes Continuous Workout Mortgage contracts offered to this individual under different house price volatility market scenarios and as a function of the prepayment rate $\lambda$. It combines these two types of CWMs in three market scenarios encompassing low and high volatilities. 


\section{INSERT FIGURE C.6 ABOUT HERE.}

The adopted range of the prepayment rate $\lambda$ allows computations for different types of individuals, according to how likely they are to prepay their mortgage. Our range encompasses $50 \%, 100 \%, 200 \%$ and $400 \%$ multiples of the long-term standard PSA value of $6 \%$ annual prepayment rate $(\lambda=0.06)$. This results in values for $\lambda$ which are 0.03 (less likely to prepay than average), 0.06 (average), 0.12 (twice as likely to prepay as average) and 0.24 (four times more likely to prepay compared to average).

When volatility is low $(\sigma=1 \%)$ the probability of a continuous workout being triggered is low. From Figure C.6 it is clear that in this case the lender expects to make money on customers prepaying early, because these homeowners are charged the prepayment penalty. A zero-profit bank should pass on this gain to customers by offering a lowered interest on these CWM mortgages up front.

When volatility is moderate $(\sigma=5 \%)$ the probability of continuous workout being triggered increases. Figure C.6 suggests that this will be reflected in the contract rate $i$ of the CWM which has to be increased even for customers not expected to prepay $(\lambda=0)$. However, the contract rate $i$ can still be reduced by introducing a prepayment penalty.

Higher volatilities $(\sigma=10 \%)$ will mean yet more protection offered to customers but at a higher cost reflected in further increases of the CWM contract rate $i$. Only for customers with sufficiently high prepayment rates $\lambda$ can the contract rate $i$ be reduced.

As intuitively expected, higher volatility and higher prepayment rates will typically mean increased risks to the lender (workout risk, prepayment risk). This will result in charging a higher contract rate $i$ up front. However, for realistic market parameter values, increases of contract rate $i$ are moderate rather than dramatic (e.g. increase by up to $0.1 \%$ on average, when rates are in the range of 10\%). Furthermore, these increases can be further moderated by introducing early prepayment penalties, as is practiced in most mortgage contracts. Figure C.7 illustrates this point further by plotting combinations of early prepayment parameters $\alpha$ and $T^{*}$ for different levels of prepayment intensity $\lambda$, for which the contract rate $i$ of a Continuous Workout Mortgage remains "preserved" i.e. equal to $i=10 \%$. 


\section{INSERT Figure C.7 ABOUT HERE.}

The above illustration explains the model from a real world perspective. In the next section, we conclude the paper.

\section{Concluding Remarks}

The current financial crisis has increased the awareness regarding susceptibility of the economy to fragile plain vanilla mortgages. This paper thus attempts to mitigate this fragility by studying Continuous Workout Mortgages (CWMs). As pointed out by Shiller (2008b), (2008a) and (2009b), these are related to Price Level Adjusting Mortgages (PLAMs), advocated by Franco Modigliani (1974) for high inflation regimes. CWMs share some positive attributes with PLAMs (such as purchasing power risk) and mitigate other negative attributes (such as default risk, interest rate risk and prepayment risk). The only residual risk attributed to CWMs is liquidity risk. This too can be alleviated by employing CWMs in sufficient volume to warrant their securitization, in which case the formulæ developed here could be used to estimate the price of a security package whose components have common risk factors.

We demonstrate how different variants of Continuous Workout Mortgages can be offered to homeowners as an ex ante solution to non-anticipated real estate price declines. If workouts are part of the original mortgage contract, then they can be done continually, systematically, and automatically, eliminating the delays, irregularities and uncertainties that are seen with the workouts we have observed in the subprime crisis. A great deal of human suffering at a time of economic contraction would be eliminated. (Shiller (2009b), Article 4, p. 11.)

We model a variety of Continuous Workout Mortgages, including interest-only and repayment contracts. For repayment CWMs we extend our analysis to include two negotiable and adjustable parameters: a workout proportion $\alpha$ and a protection threshold $\bar{K}$. The workout proportion $\alpha$ enables the workout protection to change its fractional action, while the protection threshold can be set so as the workout starts (and stops) working below (above) a specific level $\bar{K}$.

An interest-only CWM protects both (a) interest payments and (b) terminal repayment 
against declines of property value. The insurance for this is paid for via interest $i$ which is increased above $r$ (the riskless rate in our examples).

A repayment CWM protects against declines in property value. As there is no terminal repayment, this mortgage protects intermediate repayments $R_{\alpha}\left(h_{t}\right)$, which decrease as house price decreases. The premium of this insurance is incorporated into higher maximal repayment flow parameter $\rho$, established ex ante. Furthermore, a repayment mortgage, and thus a continuous workout repayment mortgage, has the advantage of reducing moral hazard. This is due to the earlier repayment of the loan's principal.

The main contributions of this paper thus are: (a) simple modelling of variants of CWMs and (b) closed form formulae for key parameters of CWMs. For repayment contracts, we provide expressions for mortgage balances and payments. For interest-only CWMs, we provide expressions for mortgage interest. These formulae are of key importance for potential originators of CWMs. Our results help in the understanding the mechanics of CWMs and estimation of key contract parameters for providing the protection level to borrowers in the form of protection threshold. Employment of CWMs should therefore be recommended to improve the resilience of the financial system to systemic risk. These will reduce exposure of governments to bailout risks and will enhance the quality of life of agents in the economy by reducing frictions. 
Ambrose, B.W., Buttimer, Jr., R.J., 2012. The adjustable balance mortgage: Reducing the value of the put. Real Estate Economics 40, forthcoming.

Berman, D.K., 2008. Wanted: New lenders. freshly created banks might cure mistrust. The Wall Street Journal November 26.

Bielecki, T.R., Rutkowski, M., 2002. Credit Risk: Modeling, Valuation and Hedging. Springer-Verlag, Berlin.

Black, F., Scholes, M., 1973. The pricing of options and corporate liabilities. Journal of Political Economy 81, $637-654$

Campbell, J.Y., Cocco, J.F., 2003. Household risk management and optimal mortgage choice. Quarterly Journal of Economics 118, 1449-1494.

Carr, P., Lipton, A., Madan, D., 2000. Going with the flow. Risk 13, 85-89.

Chomsisengphet, S., Pennington-Cross, A., 2006. The evolution of the subprime mortgage market. Federal Reserve Bank of St. Louis Review , 31-56.

Diamond, D.W., Rajan, R.G., 2008. The credit crisis: Conjectures about causes and remedies. Working Paper, University of Chicago.

Doms, M., Krainer, J., 2007. Innovations in mortgage markets and increased spending on housing. Working paper, Federal Reserve Board of San Francisco.

Duarte, J., McManus, D.A., 2011. Residential mortgage credit derivatives. Real Estate Economics 39, 671-700.

Ebrahim, M.S., Shackleton, M.B., Wojakowski, R.M., 2011. Participating mortgages and the efficiency of financial intermediation. Journal of Banking and Finance 35, 3042-3054.

Fabozzi, F., 2005. The Handbook of Fixed Income Securities. McGraw Hill, New York.

Feldstein, M., 2009. How to save an 'underwater' mortgage. The Wall Street Journal August 7.

Green, R.K., Wachter, S.M., 2005. The american mortgage in historical and international context. Journal of Economic Perspectives 19, 93-114.

Hosios, A., Peters, M., 1989. Repeated insurance contracts with adverse selection and limited commitment. The Quarterly Journal of Economics 104, 229-53.

Hurst, E., Stafford, F., 2004. Home is where the equity is: Mortgage refinancing and household consumption. Journal of Money, Credit, and Banking 36, 985-1014.

Leeds, E.M., 1993. The riskiness of price-level adjusted mortgages. Review of Business 15, 42-45.

Levine, R., Loayza, N., Beck, T., 2000. Financial intermediation and growth: Causality and causes. Journal of Monetary Economics 46, 31-77.

Modigliani, F., 1974. Some economic implications of the indexing of financial assets with special reference to mortgages. Paper Presented at the Conference on the New Inflation, Milano, Italy, June 24-26.

Pagès, H., 2009. Bank Incentives and Optimal CDOs. Working paper 253. Banque de France.

Reinhart, C.M., Rogoff, K.S., 2008. Banking crisis: An equal opportunity menace. Working Paper, Harvard 
University.

Shackleton, M.B., Wojakowski, R., 2007. Finite maturity caps and floors on continuous flows. Journal of Economic Dynamics and Control 31, 3843-3859.

Shiller, R.J., 1993. Macro Markets: Creating Institutions for Managing Society's Largest Economic Risks. Oxford University Press Inc., New York.

Shiller, R.J., 2003. The New Financial Order: Risk in the 21st Century. Princeton University Press, New Jersey.

Shiller, R.J., 2008a. The mortgages of the future. The New York Times September 21.

Shiller, R.J., 2008b. Subprime Solution: How Today’s Global Financial Crisis Happened and What to Do About It. Princeton University Press.

Shiller, R.J., 2009a. Derivatives markets for home prices, in: Glaeser, E.L., Quigley, J.M. (Eds.), Housing Markets and the Economy: Risk, Regulation, and Policy: Essays in Honor of Karl E. Case. Lincoln Institute of Land Policy, Cambridge, Massachusetts. chapter 2, pp. 17-33. Papers from a conference sponsored by the Lincoln Institute of Land Policy, held in December 2007.

Shiller, R.J., 2009b. Policies to deal with the implosion in the mortgage market. The Berkeley Electronic (B.E.) Journal of Economic Analysis and Public Policy 9, Article 4. Available at: http://www.bepress.com/bejeap/vol9/iss3/art4.

Shiller, R.J., Weiss, A.N., 1999. Home equity insurance. The Journal of Real Estate Finance and Economics 19, 21-47.

Smith, Jr., C.W., Warner, J.B., 1979. On financial contracting: An analysis of bond covenants. Journal of Financial Economics 7, 117-161.

Stanton, R., Wallace, N., 1998. Mortgage choice: What's the point? Real Estate Economics 26, 173-205.

Stiglitz, J.E., 1988. Money, credit, and business fluctuations. The Economic Record 64, 307-22.

Wilcox, J.A., 2009. Comments on 'policies to deal with the implosion' and 'homes and cars'. The B.E. Journal of Economic Analysis \& Policy 9, Article 7. Available at: http://www.bepress.com/bejeap/vol9/iss3/art7. 


\section{Appendix}

\section{Appendix A. Floor and Put Formulae}

Floors $P$ on flow $s$ with strike flow level $k$ for finite horizon $T$ can be computed using the following closed-form formula (see Shackleton and Wojakowski (2007)):

$$
\begin{aligned}
P\left(s_{0}, k, T, r, \delta, \sigma\right) & =E\left[\int_{0}^{T} e^{-r t}\left(k-s_{t}\right)^{+} d t\right] \\
& =A s_{0}^{a}\left(\mathbf{1}_{s_{0}<k}-N\left(-d_{a}\right)\right)-\frac{s_{0}}{\delta}\left(\mathbf{1}_{s_{0}<k}-e^{-\delta T} N\left(-d_{1}\right)\right) \\
& +\frac{k}{r}\left(\mathbf{1}_{s_{0}<k}-e^{-r T} N\left(-d_{0}\right)\right)-B s_{0}^{b}\left(\mathbf{1}_{s_{0}<k}-N\left(-d_{b}\right)\right),
\end{aligned}
$$

where

$$
\begin{aligned}
A & =\frac{k^{1-a}}{a-b}\left(\frac{b}{r}-\frac{b-1}{\delta}\right), \\
B & =\frac{k^{1-b}}{a-b}\left(\frac{a}{r}-\frac{a-1}{\delta}\right),
\end{aligned}
$$

and

$$
a, b=\frac{1}{2}-\frac{r-\delta}{\sigma^{2}} \pm \sqrt{\left(\frac{r-\delta}{\sigma^{2}}-\frac{1}{2}\right)^{2}+\frac{2 r}{\sigma^{2}}},
$$

whereas the cumulative normal integrals $N(\cdot)$ are labelled with parameters $d_{\beta}$

$$
d_{\beta}=\frac{\ln s_{0}-\ln k+\left(r-\delta+\left(\beta-\frac{1}{2}\right) \sigma^{2}\right) T}{\sigma \sqrt{T}}
$$

(different to the standard textbook notation) for elasticity $\beta$ which takes one of four values $\beta \in\{a, b, 0,1\}$.

Standard Black-Scholes (1973) puts on $S$ with strike value of $K$ can be computed using

$$
p\left(S_{0}, K, T, r, \delta, \sigma\right)=K e^{-r T} N\left(-d_{0}\right)-S_{0} e^{-\delta T} N\left(-d_{1}\right)
$$

where $d_{0}$ and $d_{1}$ can be computed using formula A.5 in which values $S_{0}$ and $K$ can (formally) be used in place of flows $s_{0}$ and $k$.

Both floor (A.1) and put (A.6) formulae assume that the underlying flow $s$ or asset $S$ follows 
the stochastic differential equation

$$
\frac{d s_{t}}{s_{t}}=\frac{d S_{t}}{S_{t}}=(r-\delta) d t+\sigma d Z_{t}
$$

with initial values $s_{0}$ and $S_{0}$, respectively. Clearly, (A.7) describes a geometric Brownian motion under risk-neutral measure where $Z_{t}$ is the standard Brownian motion, $\sigma$ is the volatility, $r$ is the riskless rate and $\delta$ is the service flow. We assume that A.7 describes the dynamics of the repayment flow $s$. Similarly, A.7) also defines the dynamics of the value $S$ of the real estate property. Alternatively, the model could be specified under the actual probability measure, extending Shiller and Weiss (1999) to allow for computation of floors, for example along the lines of Shackleton and Wojakowski (2007). 


\section{Appendix B. Tables}

\begin{tabular}{|c|c|c|c|c|c|c|}
\hline \multirow[t]{2}{*}{ Volatility $\sigma$} & \multicolumn{3}{|c|}{ Interest-only mortgage payments } & \multicolumn{3}{|c|}{ Repayment mortgage payments } \\
\hline & Standard & CWM & & Standard & CWM & \\
\hline & $r=$ const . & $\begin{array}{l}i>r \\
(\delta=1 \%)\end{array}$ & $(\delta=4 \%)$ & $\rho=R(\alpha=0)$ & $\begin{array}{l}\rho>R(\alpha= \\
(\delta=1 \%)\end{array}$ & $\begin{array}{l}=1) \\
(\delta=4 \%)\end{array}$ \\
\hline 0.025 & 5. & 5. & 5.02 & 6.44 & 6.44 & 6.46 \\
\hline 0.05 & 5. & 5.01 & 5.15 & 6.44 & 6.45 & 6.59 \\
\hline 0.075 & 5. & 5.03 & 5.36 & 6.44 & 6.48 & 6.78 \\
\hline 0.1 & 5. & 5.1 & 5.62 & 6.44 & 6.55 & 7. \\
\hline 0.125 & 5. & 5.21 & 5.9 & 6.44 & 6.67 & 7.24 \\
\hline 0.15 & 5. & 5.37 & 6.2 & 6.44 & 6.82 & 7.5 \\
\hline 0.175 & 5. & 5.57 & 6.53 & 6.44 & 7.01 & 7.78 \\
\hline 0.2 & 5. & 5.82 & 6.87 & 6.44 & 7.23 & 8.08 \\
\hline 0.225 & 5. & 6.1 & 7.24 & 6.44 & 7.47 & 8.4 \\
\hline 0.25 & 5. & 6.41 & 7.63 & 6.44 & 7.75 & 8.74 \\
\hline 0.275 & 5. & 6.76 & 8.04 & 6.44 & 8.05 & 9.1 \\
\hline 0.3 & 5. & 7.13 & 8.47 & 6.44 & 8.37 & 9.48 \\
\hline 0.325 & 5. & 7.53 & 8.93 & 6.44 & 8.72 & 9.88 \\
\hline 0.35 & 5. & 7.96 & 9.41 & 6.44 & 9.09 & 10.3 \\
\hline 0.375 & 5. & 8.42 & 9.91 & 6.44 & 9.49 & 10.8 \\
\hline 0.4 & 5. & 8.91 & 10.4 & 6.44 & 9.92 & 11.2 \\
\hline 0.425 & 5. & 9.42 & 11. & 6.44 & 10.4 & 11.7 \\
\hline 0.45 & 5. & 9.96 & 11.6 & 6.44 & 10.9 & 12.3 \\
\hline 0.475 & 5. & 10.5 & 12.2 & 6.44 & 11.4 & 12.8 \\
\hline 0.5 & 5. & 11.1 & 12.8 & 6.44 & 11.9 & 13.4 \\
\hline
\end{tabular}

Table B.1: Annual payments when the current interest rate is $r=5 \%$. Interest-only and repayment continuous workouts compared to the corresponding fixed-rate (interest-only and repayment) mortgages for different values of service flow $\delta=1 \%$ and $\delta=4 \%$. Fixed rate $(r=5 \%)$ mortgage payments do not depend on the service flow $\delta$. Initial loan balance, $Q_{0}$, is normalized to $\$ 100$ thousand. 


\begin{tabular}{|c|c|c|c|c|c|c|}
\hline \multirow[t]{2}{*}{ Volatility $\sigma$} & \multicolumn{3}{|c|}{ Interest-only mortgage payments } & \multicolumn{3}{|c|}{ Repayment mortgage payments } \\
\hline & Standard & CWM & & Standard & CWM & \\
\hline & $r=$ const. & $\begin{array}{l}i>r \\
(\delta=1 \%)\end{array}$ & $(\delta=4 \%)$ & $\rho=R(\alpha=0)$ & $\begin{array}{l}\rho>R(\alpha \\
(\delta=1 \%)\end{array}$ & $\begin{array}{l}=1) \\
(\delta=4 \%)\end{array}$ \\
\hline 0.025 & 10. & 10. & 10. & 10.52 & 10.52 & 10.52 \\
\hline 0.05 & 10. & 10. & 10.01 & 10.52 & 10.53 & 10.53 \\
\hline 0.075 & 10 . & 10.01 & 10.03 & 10.52 & 10.54 & 10.56 \\
\hline 0.1 & 10 . & 10.03 & 10.09 & 10.52 & 10.56 & 10.62 \\
\hline 0.125 & 10. & 10.07 & 10.18 & 10.52 & 10.6 & 10.72 \\
\hline 0.15 & 10. & 10.14 & 10.33 & 10.52 & 10.67 & 10.86 \\
\hline 0.175 & 10. & 10.24 & 10.52 & 10.52 & 10.78 & 11.06 \\
\hline 0.2 & 10. & 10.38 & 10.76 & 10.52 & 10.92 & 11.29 \\
\hline 0.225 & 10. & 10.55 & 11.03 & 10.52 & 11.09 & 11.56 \\
\hline 0.25 & 10 . & 10.77 & 11.35 & 10.52 & 11.31 & 11.87 \\
\hline 0.275 & 10. & 11.03 & 11.71 & 10.52 & 11.56 & 12.21 \\
\hline 0.3 & 10. & 11.32 & 12.1 & 10.52 & 11.85 & 12.58 \\
\hline 0.325 & 10. & 11.66 & 12.52 & 10.52 & 12.18 & 12.98 \\
\hline 0.35 & 10. & 12.03 & 12.97 & 10.52 & 12.53 & 13.42 \\
\hline 0.375 & 10. & 12.44 & 13.45 & 10.52 & 12.93 & 13.88 \\
\hline 0.4 & 10. & 12.88 & 13.97 & 10.52 & 13.35 & 14.37 \\
\hline 0.425 & 10. & 13.36 & 14.51 & 10.52 & 13.81 & 14.89 \\
\hline 0.45 & 10. & 13.87 & 15.08 & 10.52 & 14.3 & 15.44 \\
\hline 0.475 & 10. & 14.42 & 15.69 & 10.52 & 14.82 & 16.01 \\
\hline 0.5 & 10. & 15. & 16.32 & 10.52 & 15.37 & 16.62 \\
\hline
\end{tabular}

Table B.2: Annual payments when the current interest rate is $r=10 \%$. Interest-only and repayment continuous workouts compared to the corresponding fixed-rate (interest-only and repayment) mortgages for different values of service flow $\delta=1 \%$ and $\delta=4 \%$. Fixed rate $(r=10 \%)$ mortgage payments do not depend on the service flow $\delta$. Initial loan balance, $Q_{0}$, is normalized to $\$ 100$ thousand. 


\section{Appendix C. Figures}

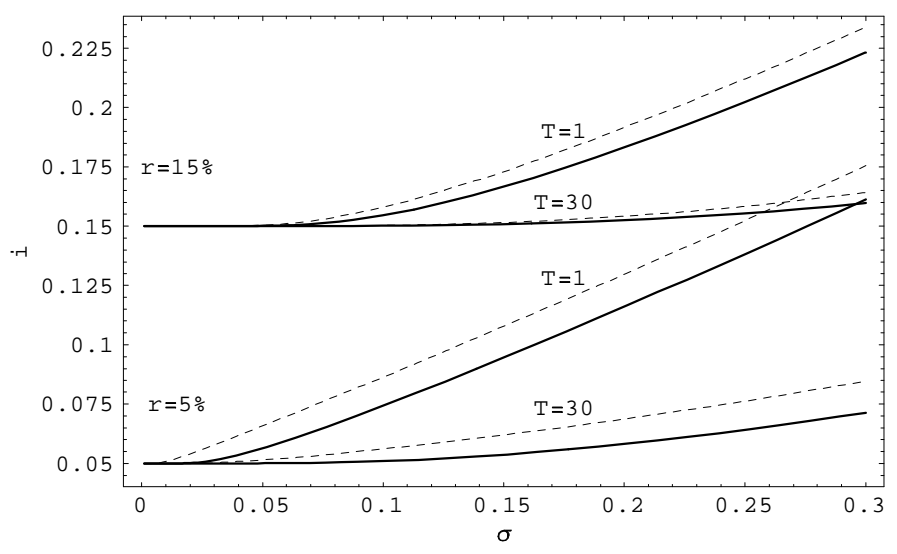

Figure C.1: Interest-only Continuous Workout Mortgage. Required interest $i$ as a function of risk $\sigma$. Tenure is $T=30$ years or $T=1$ years to maturity, riskless rates are $r=5 \%$ and $r=15 \%$ and service flow rate is either $\delta=1 \%$ (thick lines) or $4 \%$ (dashed lines).

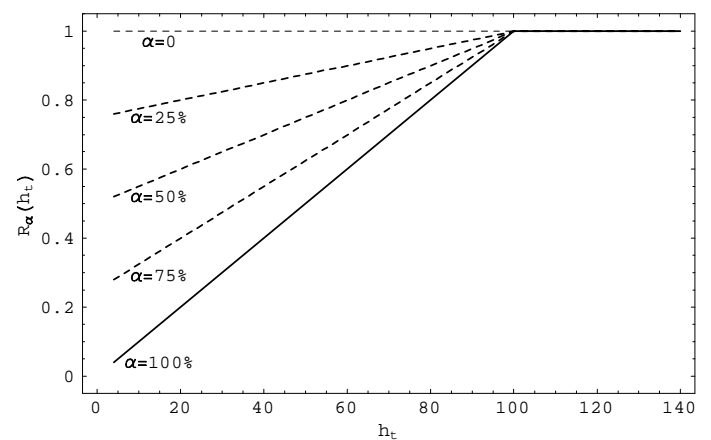

Figure C.2: Repayment Continuous Workout Mortgage (with Threshold). Reduction of mortgage payment $R_{\alpha}\left(h_{t}\right)$ as a function of current adjusted house price level $h_{t}$ and different "workout proportions" $\alpha$. Full workout is $\alpha=100 \%$ (thick solid line), no workout (standard repayment mortgage, thin dashed line) is $\alpha=0$. Maximal annual repayment (mortgage repayment parameter) is normalized to one i.e. $\rho=1$ and $h_{0}=k=100$. To illustrate the "threshold" variant of workouts assume $k=100$ and a higher starting price level e.g. $h_{0}=120$. 


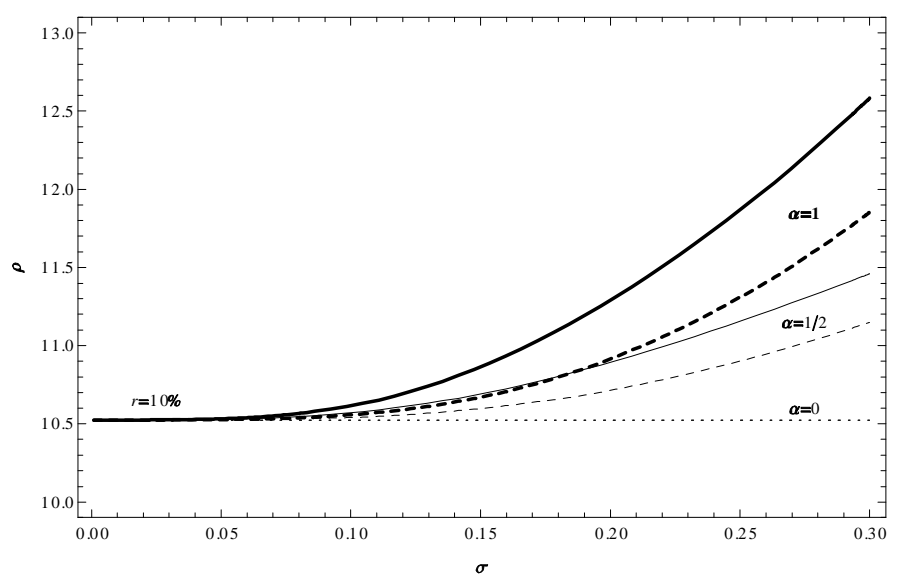

Figure C.3: Repayment Continuous Workout Mortgage. Mortgage payment $\rho$ as a function of risk $\sigma$. Partial workout ( $\alpha=\frac{1}{2}$ ) is positioned between full workout ( $\alpha=1$, thick lines) and standard repayment (no workout, $\alpha=0$, dotted flat line). Tenure is $T=30$ years to maturity, riskless rate is $r=10 \%$. Service flow rates are $\delta=1 \%$ (solid lines) or $4 \%$ (dashed lines).

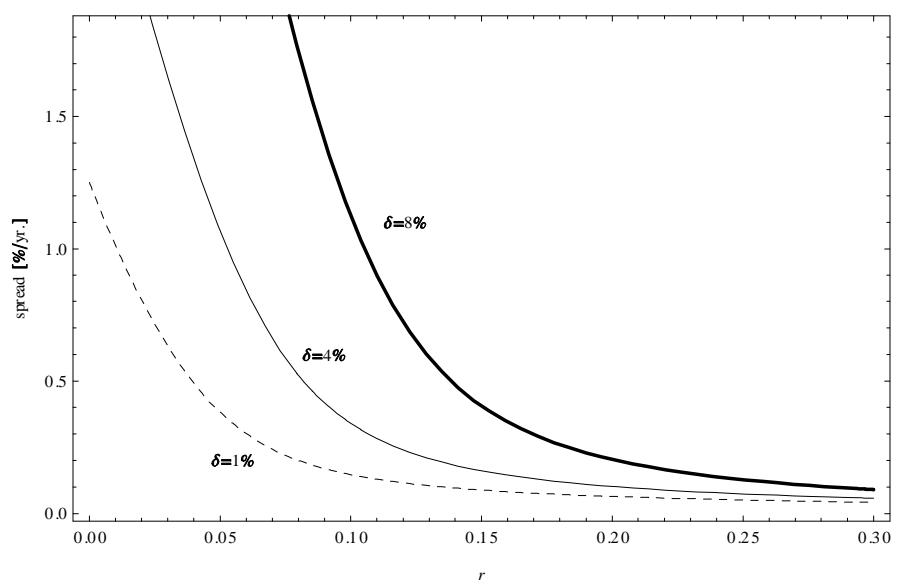

Figure C.4: Repayment Continuous Workout Mortgage. Mortgage payment spread $\rho_{\alpha}-$ $r H_{0}(1-\exp (-r T))^{-1}$ as a function of interest rate $r$ for full workout $(\alpha=1)$. Tenure is $T=30$ years to maturity, service flow rates are $\delta=1 \%$ (dashed line), $4 \%$ (solid line) and $8 \%$ (bold line). $H_{0}$ is normalized to $\$ 100$ thousand. 

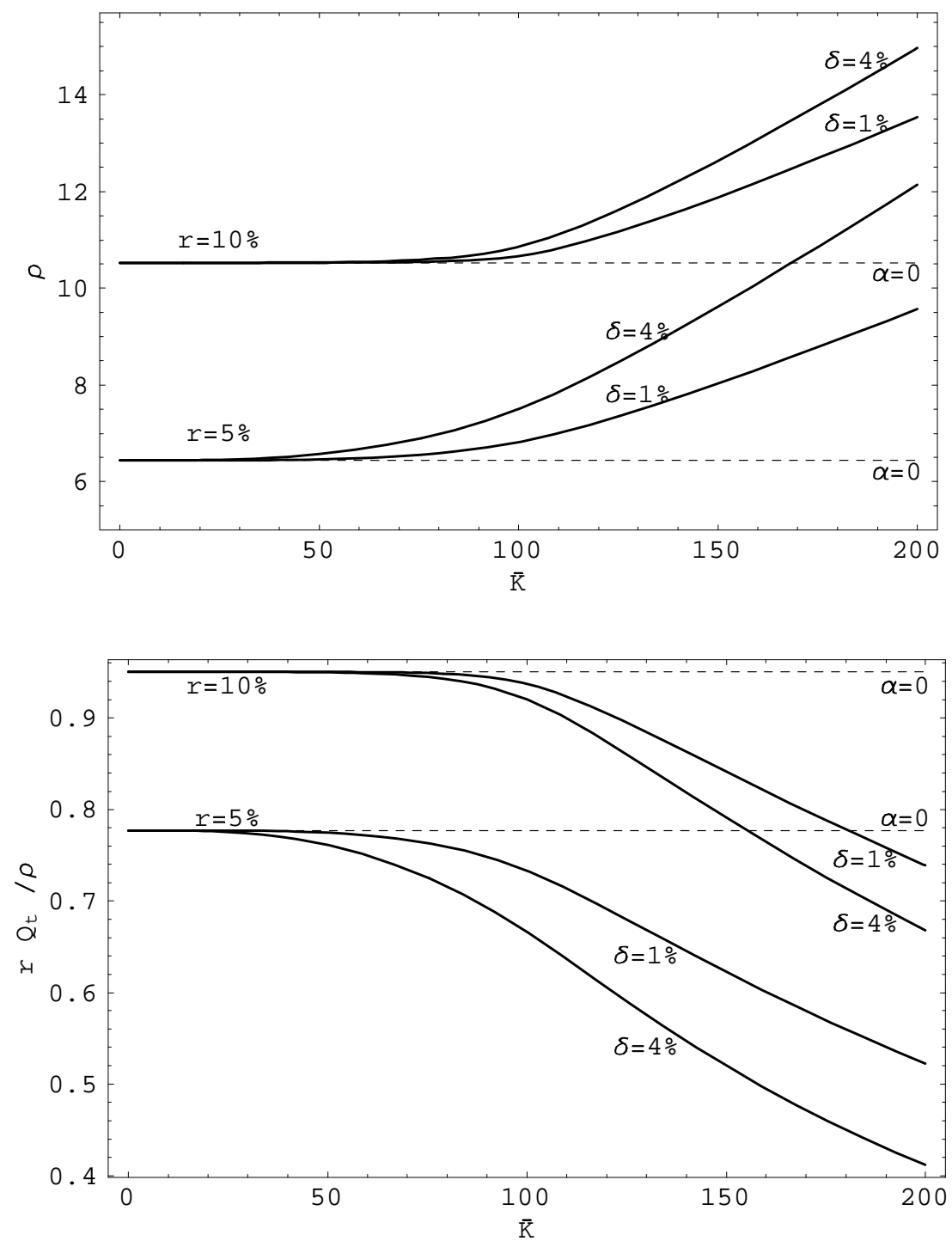

Figure C.5: Threshold Repayment Continuous Workout Mortgage (TRCWM) with threshold parameter $\bar{K}$. Increase in the mortgage payment flow $\rho$ (above) compared to reduction of mortgage balance $r Q_{t} / \rho$ (below), as a function of "workout threshold" $\bar{K}$. Interest rate $r=5 \%$ and $10 \%$, service flow rate $\delta=1 \%$ and $4 \%$, volatility $\sigma=15 \%$, term $T=30$ years to repayment, initial house price and index $\bar{H}_{0}=100$. 


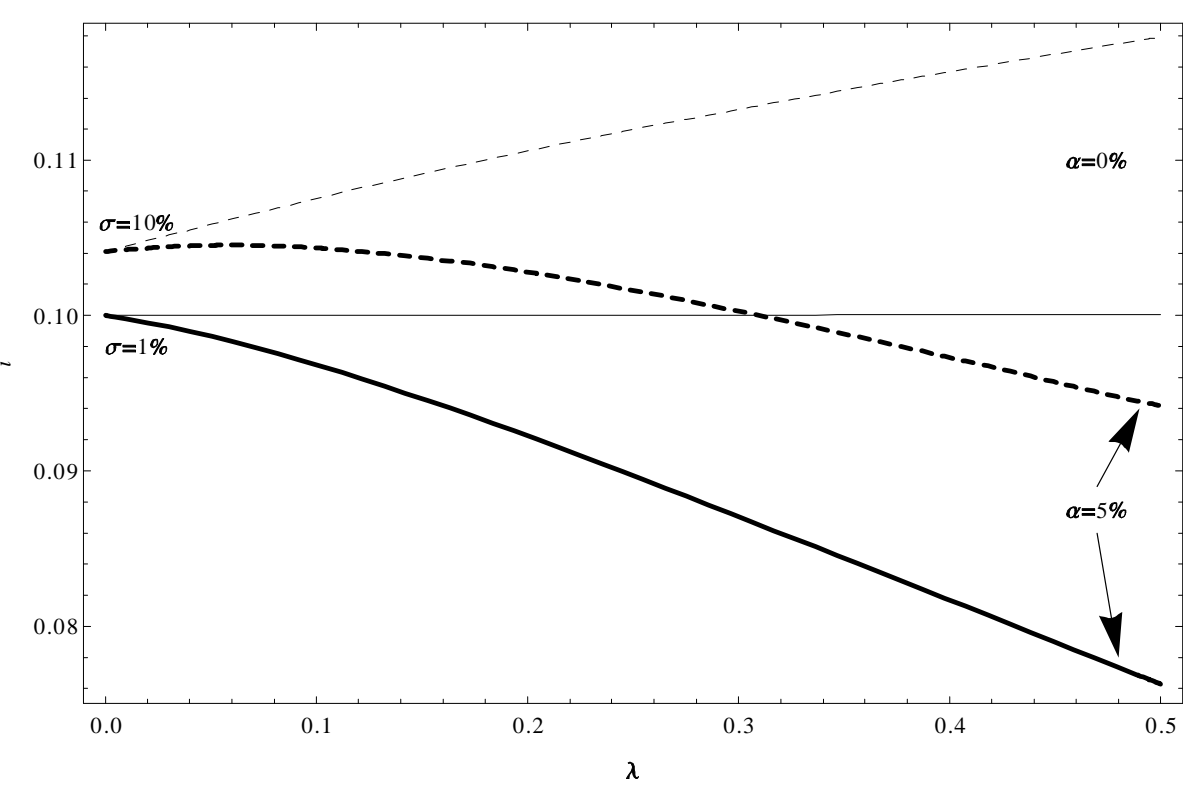

Figure C.6: Continuous Workout Mortgage contract rate $i$ as a function of the prepayment rate $\lambda$.

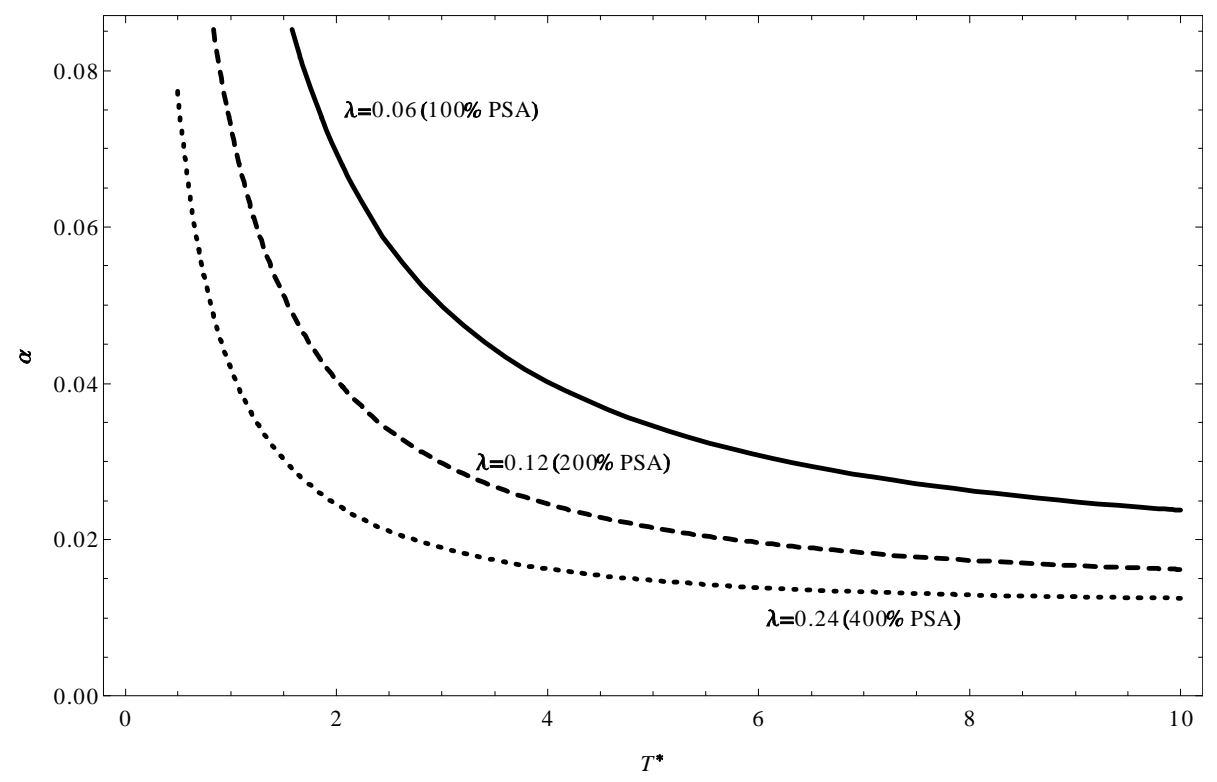

Figure C.7: Continuous Workout Mortgage contract-rate-preserving combinations (at $i=10 \%$ ) of early prepayment parameters $\alpha$ and $T^{*}$ for diffrerent levels of prepayment intensity $\lambda$. 